\title{
A Versatile Multi-Level Converter Platform for Cancer TREATMENT USING IRREVERSIBLE ELECTROPORATION
}

\author{
${ }^{1}$ Héctor Sarnago, Member, IEEE, ${ }^{1}$ Óscar Lucía, Senior Member, IEEE, \\ ${ }^{1}$ Alejandro Naval, ${ }^{1}$ José M. Burdio, Senior Member, IEEE, ${ }^{2}$ Quim Castellvi, and ${ }^{2}$ Antoni Ivorra \\ ${ }^{1}$ Department of Electronic Engineering and Communications \\ Universidad de Zaragoza \\ Maria de Luna, 1. Zaragoza 50018. Spain. \\ E-mail: olucia@,unizar.es \\ ${ }^{2}$ Department of Information and Communication Technologies \\ Universitat Pompeu Fabra \\ Carrer Roc Boronat 138, Barcelona 08018. Spain.
}

\section{Corresponding author: Óscar Lucía}

Department of Electronic Engineering and Communications. University of Zaragoza.

Maria de Luna, 1. Zaragoza 50018. Spain.

Tel. +348765319

E-mail: olucia@unizar.es

Abstract - Electroporation is an effective technique based on applying an electric field to cells commonly used to increase the effectivity of drug and gene delivery. When the applied electric field is strong enough, it can be used for selective cell death with promising results in cancer treatment. This paper proposes the development of a modular multi-level topology in order to provide a high-performance tool for research in electroporation. The proposed converter based on a scalable multi-cell approach is detailed and analyzed in this paper, and an experimental prototype has been designed and built. The experimental results prove the feasibility of this proposal to enable advanced electroporation techniques.

Keywords-Electroporation, multi-level converter, power electronics 


\section{INTRODUCTION}

Cancer treatment is a priority among multidisciplinary researchers worldwide due to its extreme impact in our current society. Classical treatment techniques include chemotherapy/immunotherapy, radiotherapy and surgery, which are often combined to obtain better results [1]. However, with more than 100 different types of cancer [2] which evolve differently in each body, it is difficult to obtain a universal optimum therapy. In order to address this colossal challenge, new techniques have arisen in the last decade either to provide better results or treat cancer cases which are not possible to treat using conventional techniques. Among these techniques, hyperthermia, stem cell transplant, photodynamic/laser therapy and electroporation are some of the most promising ones.

Currently, power electronics play a key role in medical applications [3] enabling the development of new equipment for diagnosis, monitoring, treatment, and implants $[4,5]$. In particular, power electronics is essential in electroporation research, enabling the implementation of new equipment able to help doctor and patients in the search of a cure.

This paper focuses on the development of a versatile multi-level platform [6] for cancer treatment using irreversible electroporation. Electroporation $[7,8]$ is a technique described in the 1980s $[9,10]$ based on applying an intense electrical field to living tissues to induce physiological changes $[11,12]$. Electroporation is commonly applied to increase the cell permeability and, as a consequence, facilitate the drug delivery process [13]. The electric field applied, $E$, to observe the cell reversible electroporation must be above a minimum limit, $E_{\text {rev }}$. However, when the applied electrical field is high enough, the changes made are permanent and lead to apoptosis, i.e. cell death, and the technique is called Irreversible Electroporation (IRE) [14-16] (Fig. 1). The electric field applied in irreversible 
electroporation is higher than a minimum limit, $E_{\text {irrev }}$, and lower than $E_{\text {thermal }}$, where the thermal heating due to resistive losses become predominant. IRE has arisen lately as a promising non-invasive treatment for those tumors difficult to treat by other means $[17,18]$, especially in liver tissues.

Previous biomedical studies have reported that, in order to achieve IRE, it is required an electric field exceeding $1 \mathrm{MV} / \mathrm{m}$ with fast rising times [14, 19-21]. Besides, the application of bipolar pulses has been identified as a promising technique with improved results. These requirements, combined with a wide set of possible treatments based on different application times and modulation techniques, requires the development of a versatile pulse generation platform. In the past, several topologies have been proposed for electroporation with different applications [22, 23]. The Marx generator [24, 25] is often proposed for food processing at industrial scale, but lacking the controllability required for medical applications. In [26], a 2$\mathrm{kV}$ MOSFET based converter, limited to $2.15 \mathrm{MV} / \mathrm{m}$. Besides, in order to provide proper pulsed power, pulse forming networks (PFN) have been proposed [27], being the Blumlein topology [28] commonly adopted. Besides, considering the potential scalability of the problem, a 1-kV modular voltage source has been also proposed in [29]. 


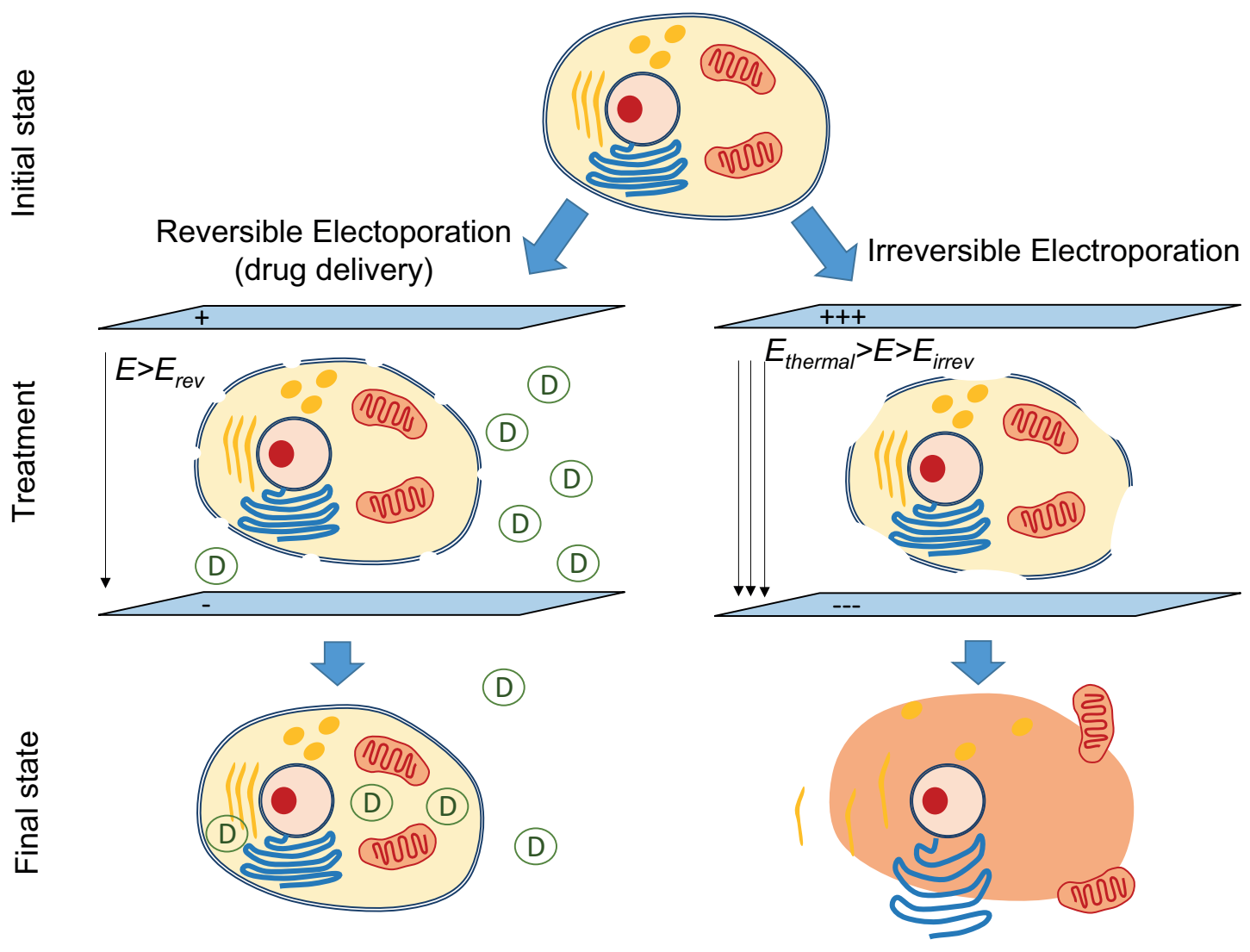

Fig. 1. Electroporation: (a) reversible and (b) irreversible phenomena.

Currently, commercial generators for biomedical applications are available up to $3 \mathrm{kV}$ with unipolar pulses and limited controllability. In this paper, a versatile multi-level inverter is proposed, being able to scale the output power beyond this limit with bipolar pulses, faster rising times and fully programmable pulses.

The remainder of this paper is organized as follows. Section II presents the basic techniques and requirements for IRE. Section III presents the proposed modular multi-level topology designed following the requirements of irreversible electroporation. Section IV analyzes the converter operation and details the design of the main elements. Section V shows the main implementation and experimental results of a scaled prototype and, finally, Section VI draws the main conclusions of this paper. 


\section{IRREVERSIBLE ELECTROPORATION CONSIDERATIONS}

Irreversible electroporation (IRE) is a non-thermal focal technique based on applying a strong electrical field to living cells to cause irreversible electroporation leading to apoptosis. Unlike heating or drugs based methods, IRE is a minimally invasive technique where collateral damage is minimized since the surrounding tissue is not affected and no drugs are introduced into the patient general system.

In order to achieve IRE, high electrical field strength $E_{\text {irrev }}$ must be achieved which ranges from typical values up to $2.5 \mathrm{kV} / \mathrm{cm}$ for mammalian cells, to $12 \mathrm{kV} / \mathrm{cm}$ for plant cells, and up to $24 \mathrm{kV} / \mathrm{cm}$ for bacteria. In this paper, the power converter will be designed considering a 1-cm sample of mammalian cells aiming to enable research in human cancer treatment.

In addition to the voltage level, i.e. electric field strength, the applied waveform has a direct impact on the effects of the treatment. Fig. 2 summarizes the voltage waveform commonly applied by most electroporation generators. Many of them are based on capacitor discharge and, consequently, the voltage follows an exponential decay as shown in Fig. 2(a). However, in order to obtain more repeatable and stable results, modern generators are based on squarewave generators, applying a constant voltage. This technology started by applying monopolar high-voltage pulses (Fig. 2(b)), but recent research results suggest that the use of bipolar high-voltage pulses may increase the effectivity of the treatment (Fig. 2(c)). In both cases, the slew rate is an important design factor, being essential to ensure a high peak current. 


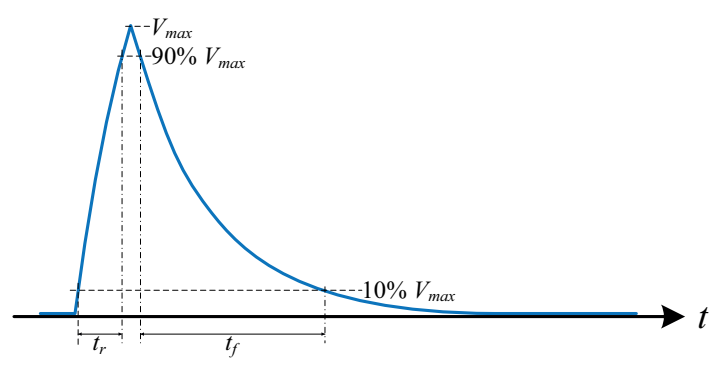

(a)

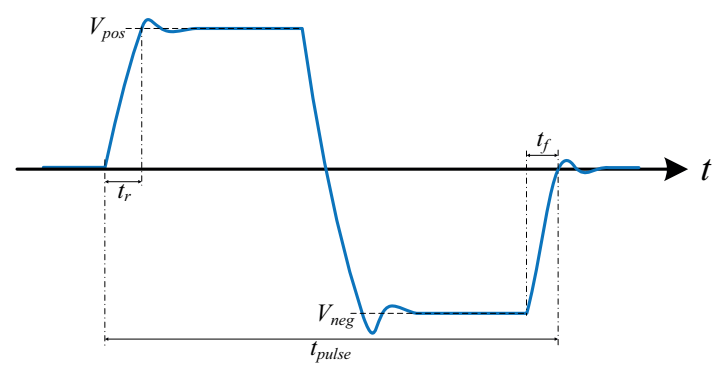

(c)

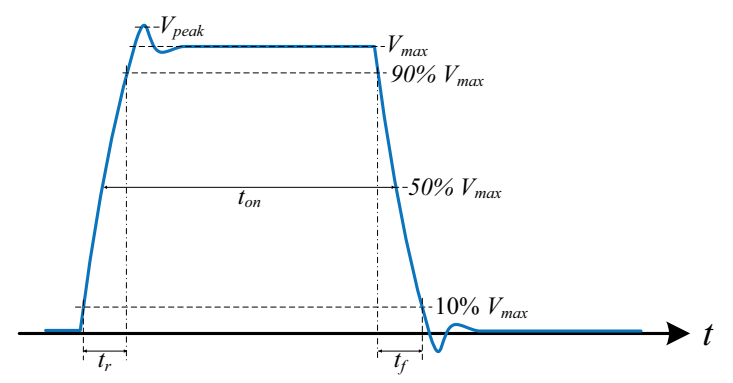

(b)

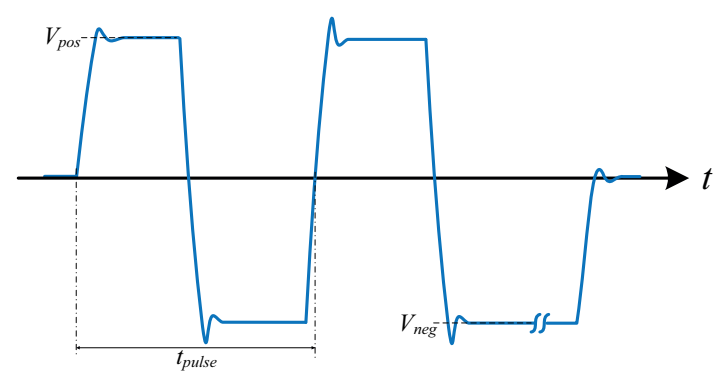

(d)

Fig. 2. High-voltage pulses for IRE: (a) exponential decay, (b) square-wave monopolar pulse, (c) square-wave bipolar pulse, and (d) square wave bipolar pulse train.

The complete treatment is normally composed of several pulses generated using one of the aforementioned techniques. These pulses are combined to form a pulse train, also called burst-mode or pulse density modulation (Fig. 2(d)). Pulse width for IRE in mammalian cells usually range from $1 \mu$ s to several hundreds of $\mu$ s, whereas the number of pulses is variable from 1 to 100 .

Considering the highly variable treatment conditions, as well as the necessity to obtain a reliable tool to characterize and assess IRE treatments, in this paper a converter able to supply bipolar pulses using configurable burst-mode modulations with pulse width from $1 \mu$ s and rise time lower than $10 \%$ will be considered. 
The biological electroporation load can be modeled following a simplified electrical equivalent as shown in Fig. 3. It takes into account the tissue equivalent parallel resistance, $R_{e}$, as well as the capacitive behavior of the cell membrane, $C_{m}, R_{i}, R_{m}$ [20]. When the electroporation treatment is applied, $R_{e p}$ is commonly reduced, reducing the impedance of the tissue. Usually, the time constant for electroporation process assuming a first-order response is close to $0.2 \mu \mathrm{s}$, and the maximum peak current will be considered to be 150 A to achieve a fast rise time. These values will be taken as reference load for the converter validation.

The next section details the proposed converter as well as its analysis and design process to obtain the required features for the IRE application.

\section{PROPOSED VERSATILE MULTILEVEL CONVERTER}

\section{A. Versatile multilevel architecture}

The proposed versatile multilevel converter has been designed to be a high-performance tool enabling research on IRE. Fig. 4 shows a block diagram of the complete pulse generator architecture. Firstly, a bus charge unit composed of a full-bridge inverter is used at the input to charge the bus voltage of each ac-dc-ac cell through a transformer. By following this approach, it is possible to provide the required high voltage isolation while having a high power density implementation. Compared with previous proposals, this topology ensures proper output voltage control while the modular design ensures scalability for different applications. 


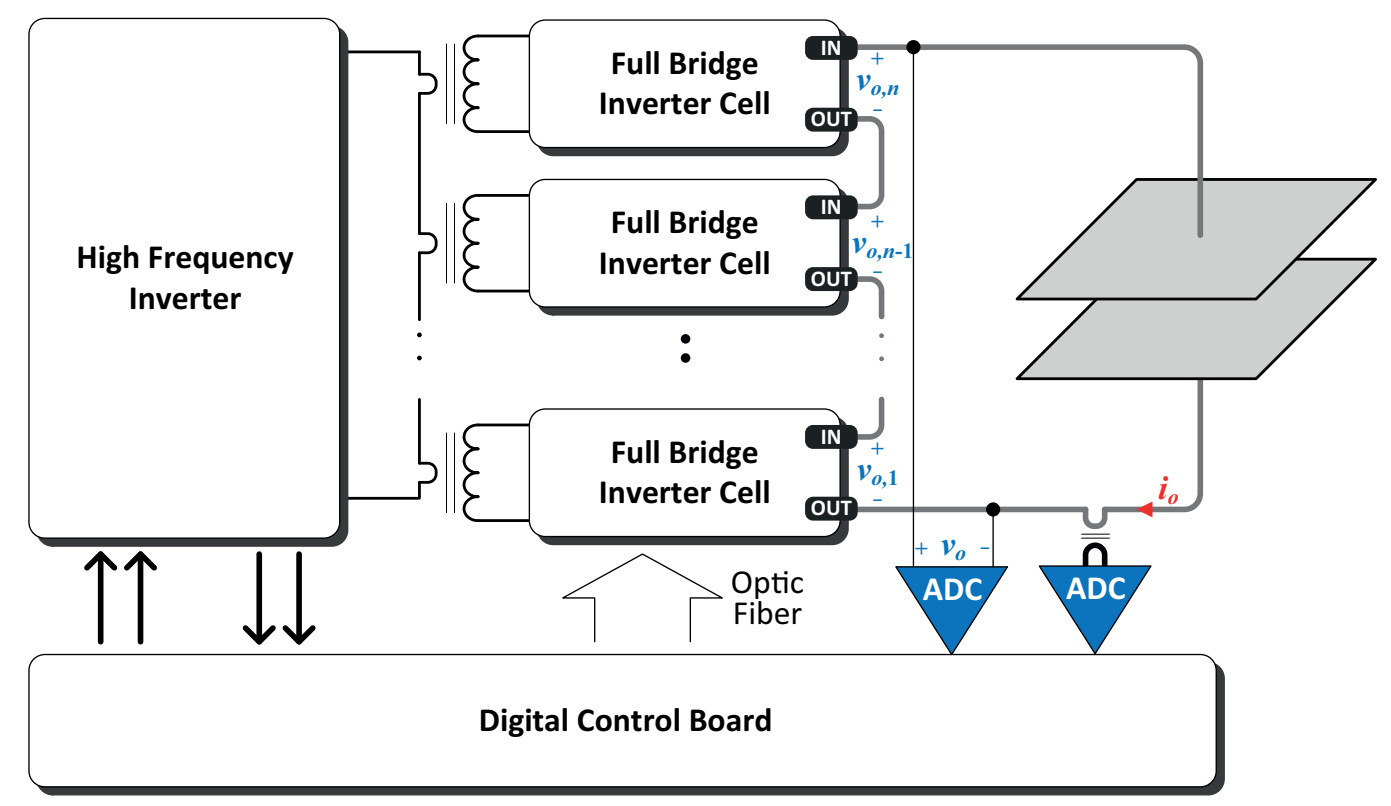

Fig. 4. Proposed versatile platform architecture.

The proposed multilevel architecture is composed of several ac-dc-ac cells which allow generating bipolar pulses. The outputs of the inverter cells, $v_{o, i}$, are connected in series, so the number of cells can be easily selected according to the output voltage requirements. Unlike previous proposals and commercial electroporation equipment, it is important to note that the proposed architecture allows generating any pulse width and pulse trains with high versatility.

Finally, the electrodes connected to the output of the inverter block can be shaped either as parallel planes, as shown in the figure, or needles. The former provides a uniform electric field, while the latter enables easier application in living tissues. In this paper, both an equivalent $R C$ circuit and parallel plane electrodes applied to plant cells will be used for test.

Finally, both the bus charge unit and the set of ac-dc-ac cells are controlled using an FPGAbased digital control architecture [30]. The FPGA enables controlling the high frequency inverter block to obtain the desired bus voltage as well as each full bridge inverter cell. The 
control signals are isolated using optic fiber in order to provide the required isolation for high voltage and high $\mathrm{d} v / \mathrm{d} t$ applications. In this application, the main parameter to be controlled is the output voltage as well as the number and shape of applied pulses, which will depend on the treatment. Besides, the output voltage and current are measured to control and evaluate important parameters of the electroporation process and in order to ensure the proper and reliable converter operation. The next subsection details the schematic and operation of each inverter cell.

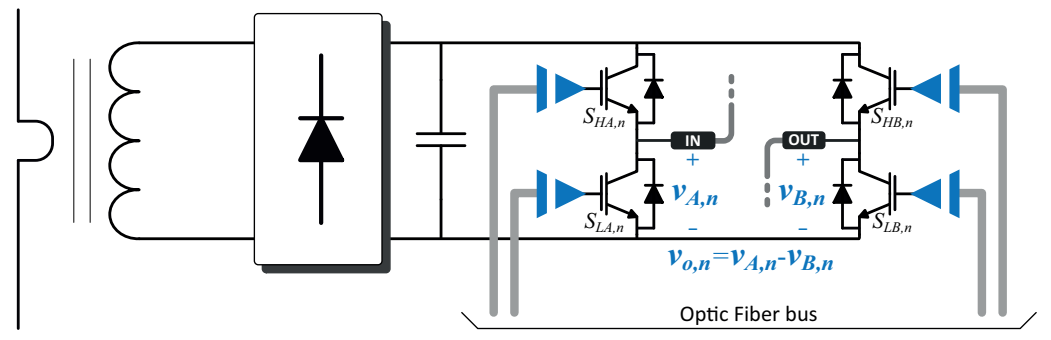

(a)

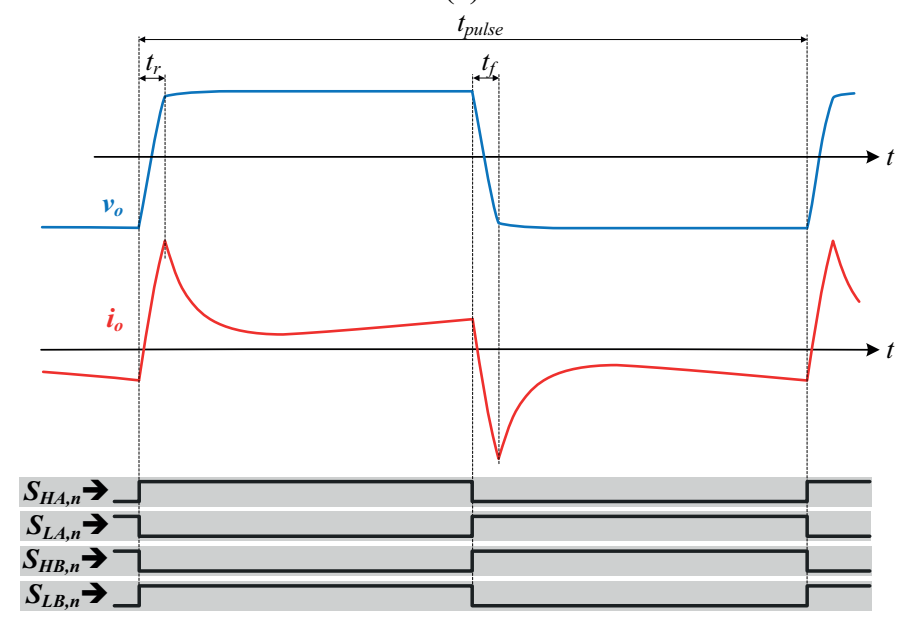

(b)

Fig. 5. Basic cell schematic (a) and main waveforms and control signals (b).

\section{B. Basic cell description}

Each ac-dc-ac cell (Fig. 5(a)) is supplied by the high frequency inverter block through a 
high frequency transformer. The input voltage is rectified and filtered $\left(C_{B, n}\right)$ in order to obtain an isolated bus voltage, $V_{B, n}$, for the inverter stage. The bus capacitor and its charging procedure must be carefully designed in order to provide enough energy for the electroporation process without significant bus voltage reduction, according to the application specifications.

The selected topology for the inverter cell is the full-bridge inverter, which enables generating bipolar pulses in an efficient way. It is composed of four transistors with antiparallel diodes, $S_{H A, n}, S_{L A, n}, S_{H B, n}$, and $S_{L B, n}$, which are designed to provide the required current pulse. For this application, IGBT technology has been selected due to the high current capability and short-circuit reliability. The driving circuit has been designed using optic fiber and isolated power supplies in order to ensure the proper isolation for high voltage applications.

The main waveforms of each inverter cell are shown in Fig. 5(b), where the control signals, the output voltage and the output current during the electroporation process are represented. As it is shown, the full-bridge inverter provides a bipolar output voltage which can be controlled by the bus voltage and the number of cascaded cells. The peak output current is limited by the $\mathrm{dv} / \mathrm{dt}$ of the converter, which is typically higher than $2 \mathrm{kV} / \mu \mathrm{s}$, and will determine, therefore, the performance of the proposed architecture. It is important to note that, due to the parallel resistance $R_{p}$, a small holding current is present after the initial transient. This ensures ZVS turn-on transition while achieving low turn-off losses. 


\section{IMPLEMENTATION AND EXPERIMENTAL RESULTS}

In order to prove the feasibility and performance of the proposed modular multi-level architecture, a high-performance 2-level converter for IRE has been designed and implemented. The full-bridge cell topology has been built using IGBTs and highperformance $1 \mathrm{kV}$ film bus capacitors, ensuring sufficient peak current capability. Besides, the transient thermal performance of TO-247 devices ensures the correct pulsed operation. Consequently, each cell can provide up to $1250 \mathrm{~V}$ bipolar output voltage. The power converter is controlled by a Spartan 6 FPGA which can be safely controlled through the USB port enabling experiment automation.

The experimental measurements have been carried out using Tektronix DPO7000 series digital oscilloscope, TCP303 current probe and P6015 high-performance high-voltage voltage probe. In order to replicate the experimental conditions of the IRE process, an RC circuit has been used as load with $R=5 \Omega$ and $C=10 \mathrm{nF}$, which emulates the ac cell behavior, leading to a peak current exceeding 150 A. Fig. 6 shows a picture of a cell of the experimental prototype used in the following experiments.

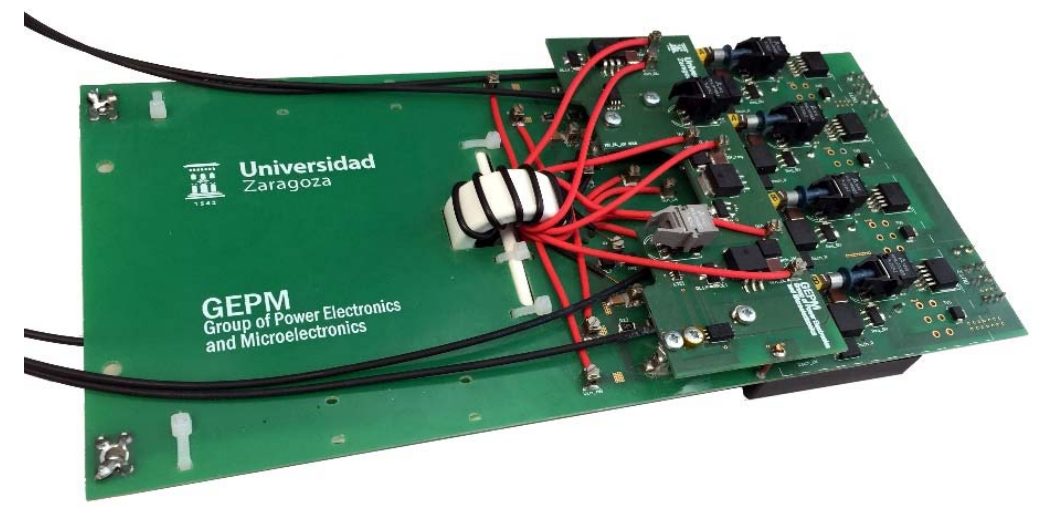

Fig. 6. Experimental prototype module. 
Fig. 7 summarizes the main experimental results for a single-cell converter using unipolar modulation. In these experiments, different pulse widths have been tested, and a detail of the peak current is given. From this experiments, the proper operation of the converter is observed with a $1 \mathrm{kV}$ output voltage and up to $100 \mathrm{~A}$.

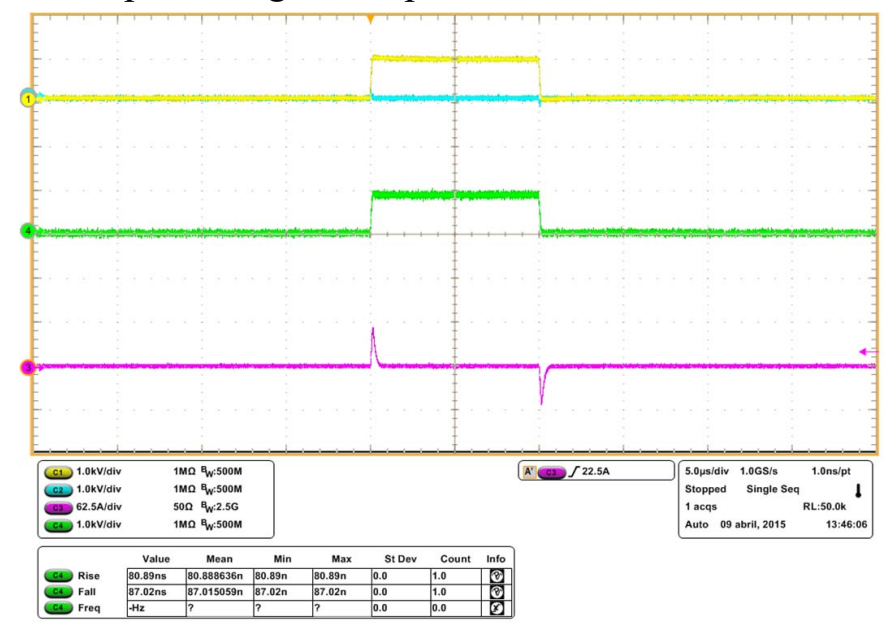

(a)

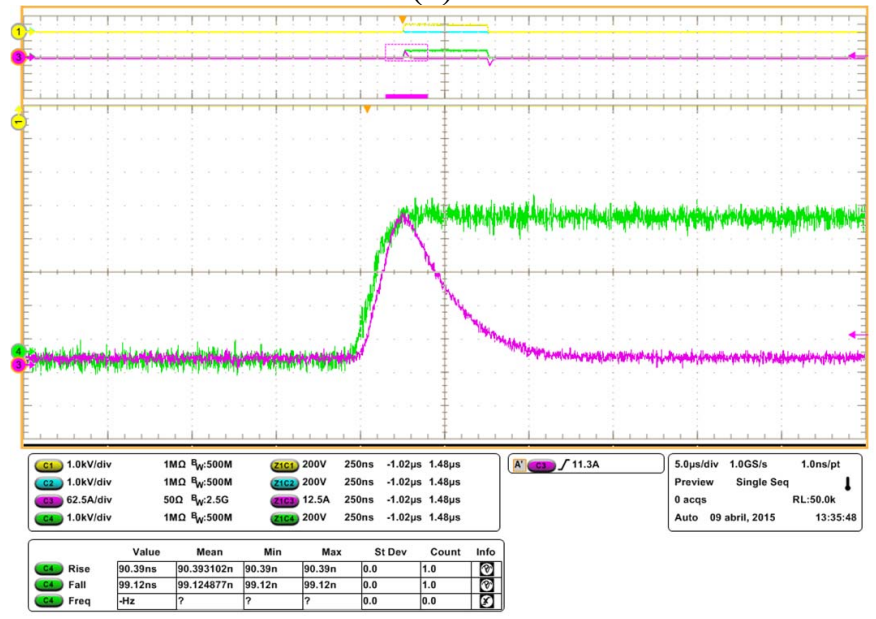

(b)

Fig. 7. Main experimental waveforms for a single cell with different unipolar modulation profiles: single-pulse $10 \mu \mathrm{s}$ (a), and detail of the positive (b). From top to bottom: inverter branches output voltages $v_{A}, v_{B}(1 \mathrm{kV} / \mathrm{div})$, cell output voltage $v_{o}(1$ $\mathrm{kV} / \mathrm{div})$, and output current $i_{o}(62.5 \mathrm{~A} / \mathrm{div})$.

In order to obtain more advanced modulations to enable research in IRE which is usually not possible with commercial products several bipolar modulations as well as pulse trains 
have been tested. Fig. 8 shows the main waveforms for $10-\mu$ s bipolar pulses (a), as well as the detail of the positive (b) current peak. In these tests, $2 \mathrm{kV}$ peak-to-peak voltage is applied, with a current peak exceeding $180 \mathrm{~A}$.

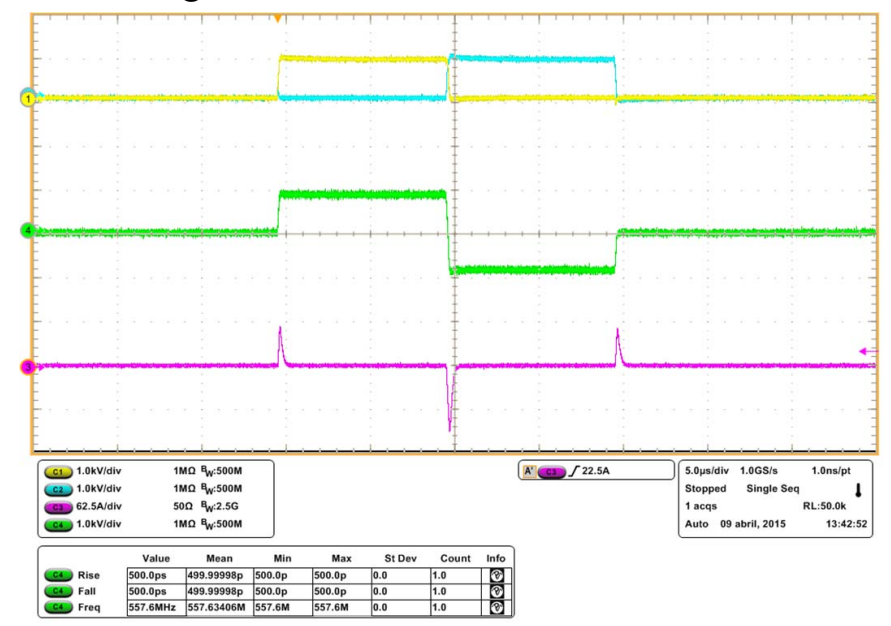

(a)

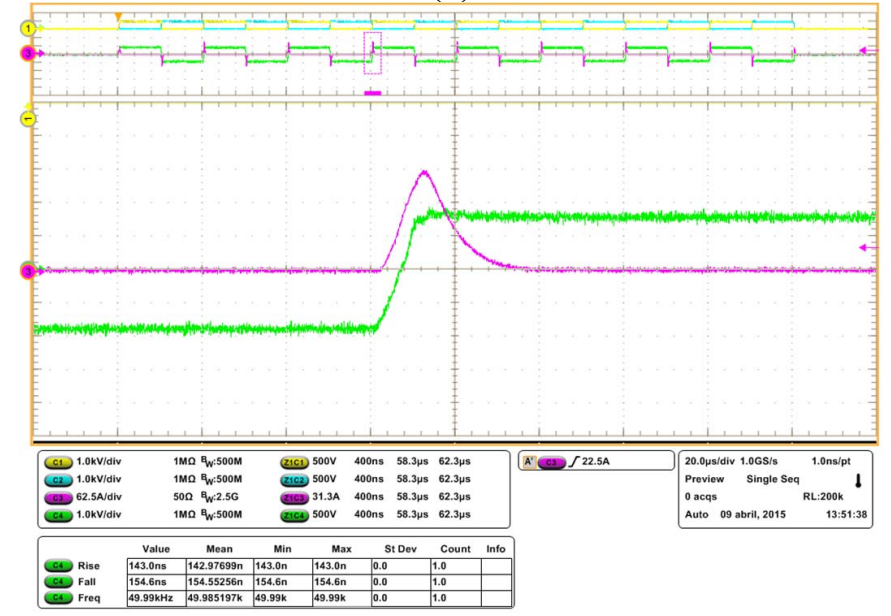

(b)

Fig. 8. Main experimental waveforms for a single cell with different bipolar modulation profiles: single-pulse $10 \mu \mathrm{s}$ (a) and detail of the positive (b) current pulse. From top to bottom: inverter branches output voltages $v_{A}, v_{B}(1 \mathrm{kV} / \mathrm{div})$, cell output voltage $v_{o}(1 \mathrm{kV} / \mathrm{div})$, and output current $i_{o}(62.5 \mathrm{~A} / \mathrm{div})$.

Besides, several pulse train modulations, also known as burst mode, have been tested and summarized in Fig. 9 for 8 pulses of $10-\mu$ s (a) and $100-\mu$ s (b), and 100 pulses of $100-\mu \mathrm{s}$ (c). These results proves the correct operation and the versatility of the proposed platform which enables new programmable modulations for research in IRE. 


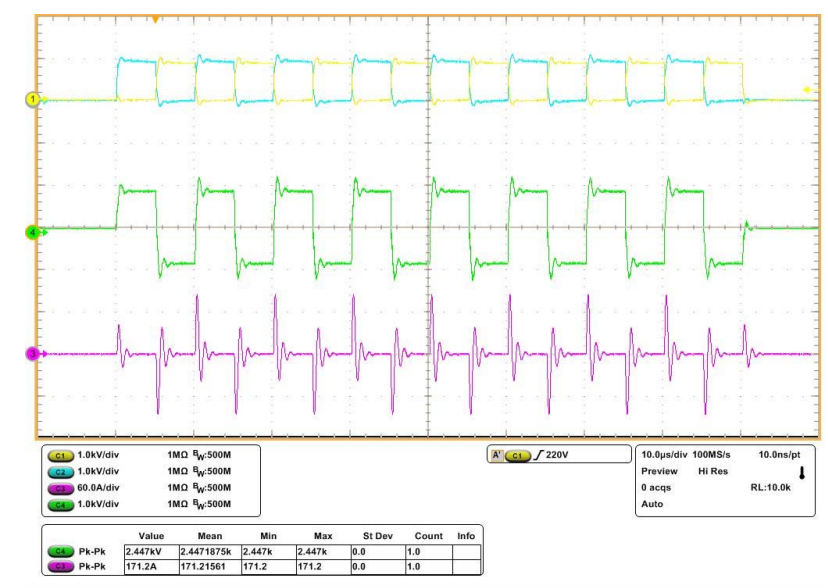

(a)

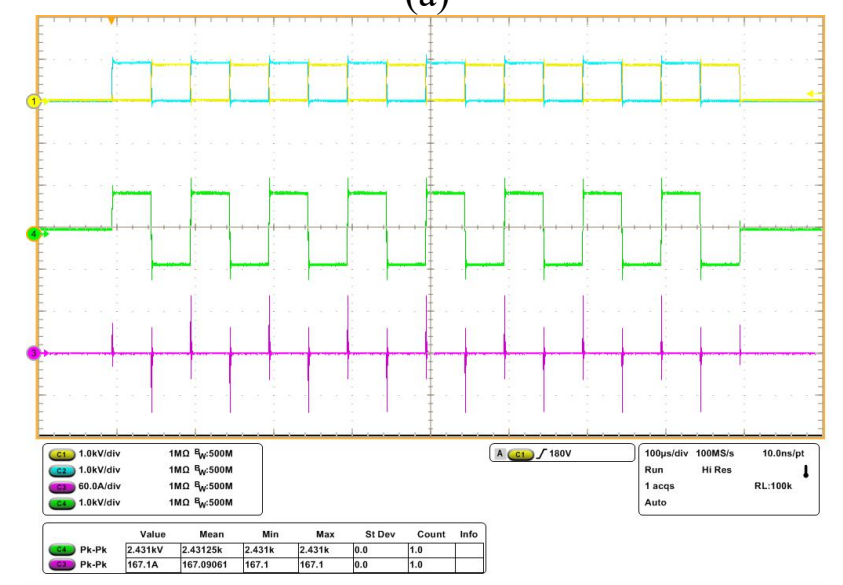

(b)

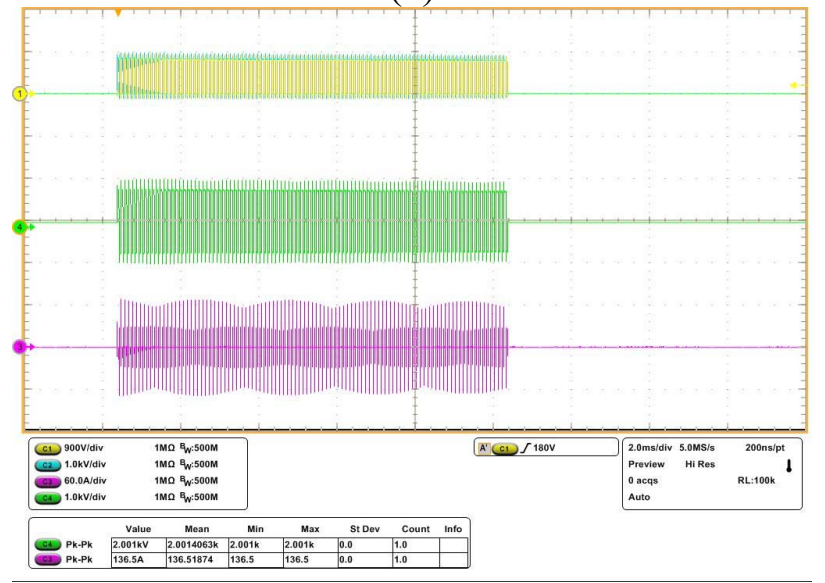

(c)

Fig. 9. Main experimental waveforms for a single cell with different bipolar pulse trains: 8-pulse train 10 - $\mu$ s width (a), 8-pulse train 100 - $\mu$ s width (b), 100-pulse train $100-\mu \mathrm{s}$ width. From top to bottom: inverter branches output voltages $v_{A}, v_{B}(1 \mathrm{kV} / \mathrm{div})$, cell output voltage $v_{o}(1 \mathrm{kV} / \mathrm{div})$, and output current $i_{o}(62.5 \mathrm{~A} / \mathrm{div})$. 
Fig. 10 shows the main experimental results for a dual-cell converter able to provide $4 \mathrm{kV}$ peak to peak voltage pulses with bipolar modulation. This converter has been tested both with unipolar (a) and bipolar (b) modulation, proving the correct operation of the cascaded operated cells. Consequently, the proposed platform is proved to be a versatile platform enabling research on IRE with increased modulation degrees of freedom as well as improved output current and voltage levels.

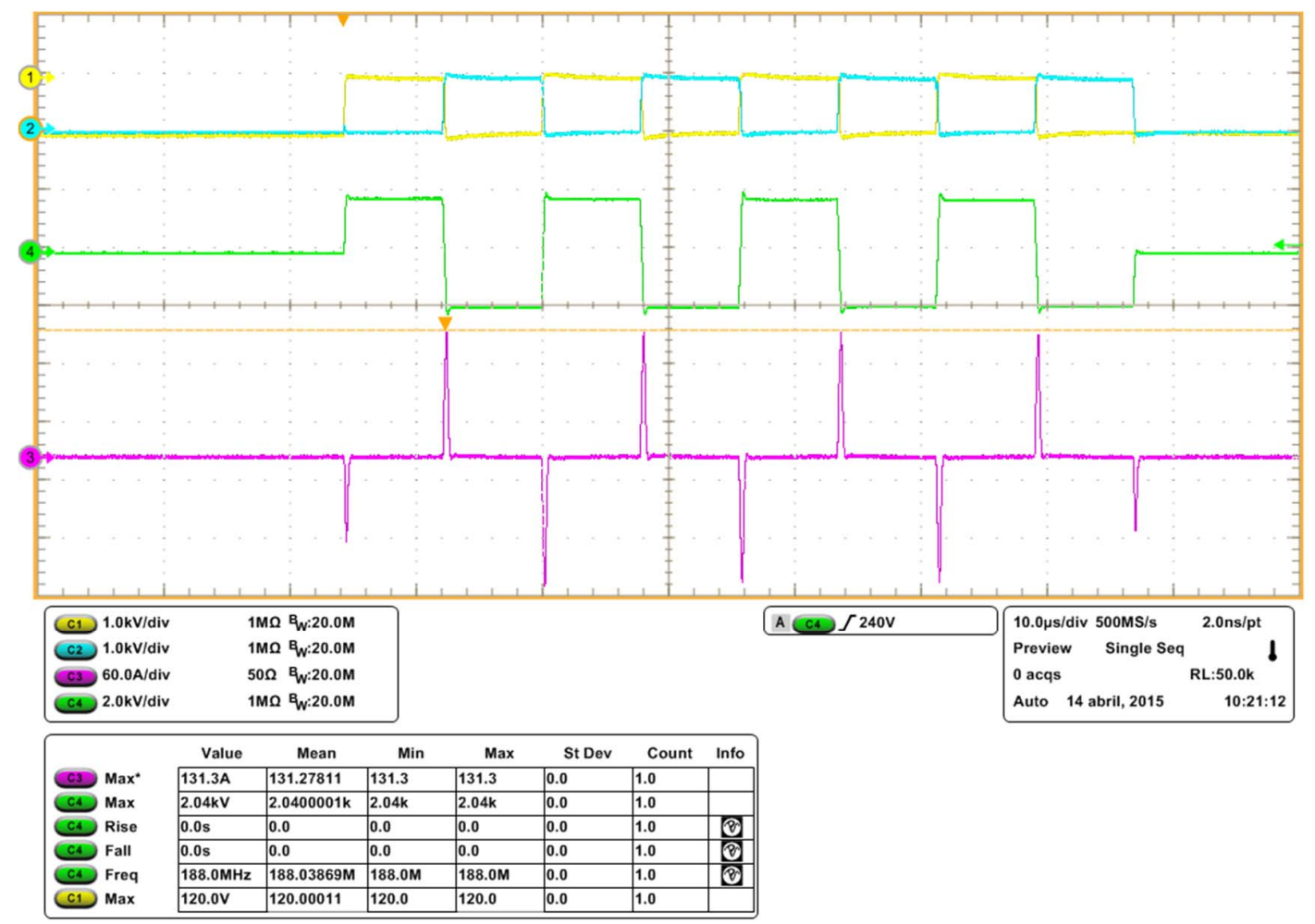

Fig. 10. Main experimental waveforms for a dual-cell converter with bipolar modulation. From top to bottom: inverter branches output voltages $v_{A}, v_{B}(1 \mathrm{kV} / \mathrm{div})$, cell output voltage $v_{o}(1 \mathrm{kV} / \mathrm{div})$, and output current $i_{o}(62.5 \mathrm{~A} / \mathrm{div})$. 


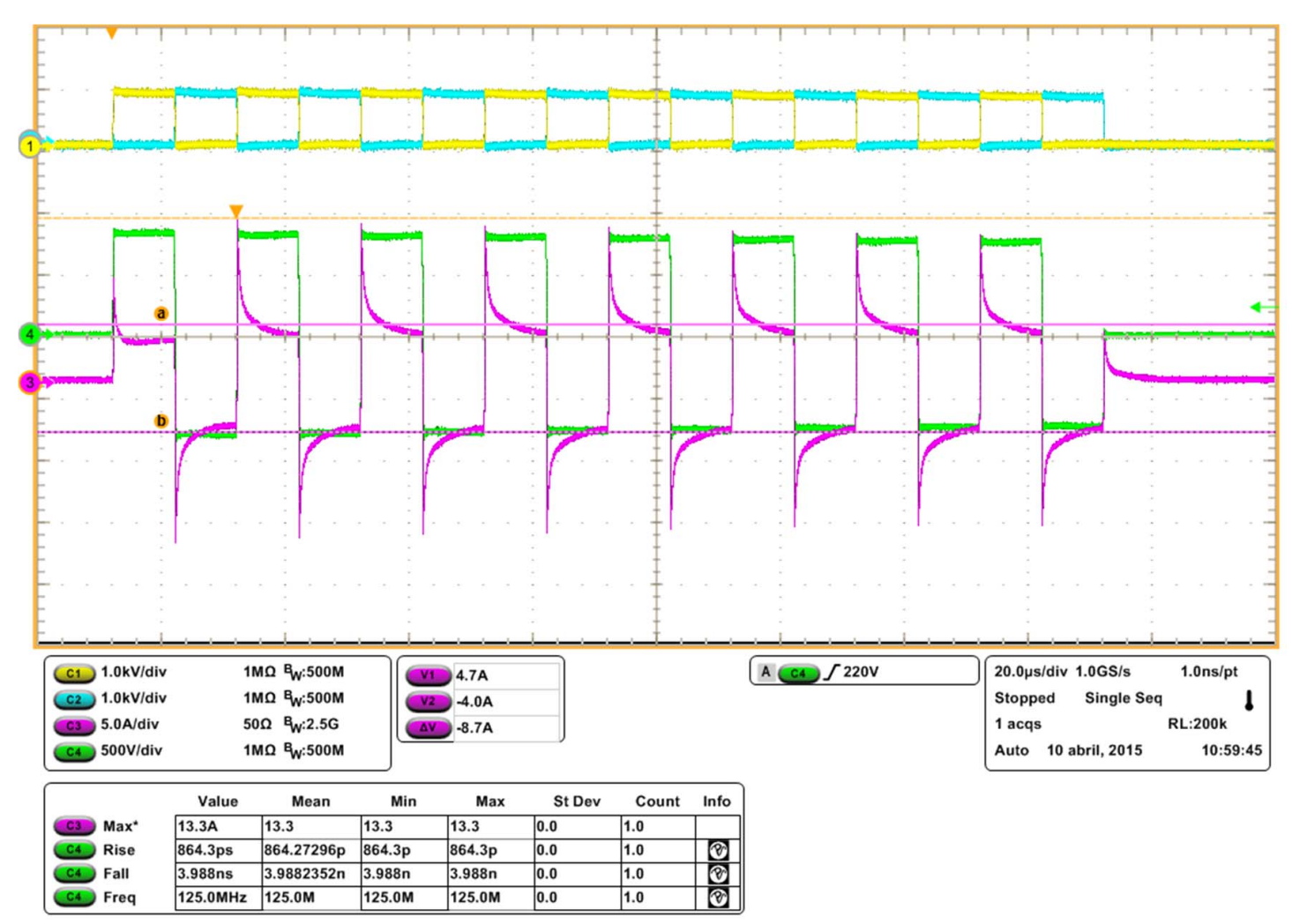

Fig. 11. Main experimental waveforms during an electroporation test using 1 $\mathrm{kV} / \mathrm{cm}$ and 5 -cm square copper electrodes on a plant tissue. From top to bottom: inverter branches output voltages $v_{A}, v_{B}(1 \mathrm{kV} / \mathrm{div})$, cell output voltage $v_{o}(1 \mathrm{kV} / \mathrm{div})$, and output current $i_{o}(62.5 \mathrm{~A} / \mathrm{div})$.

Finally, Fig. 11 shows an electroporation experiment using 5-cm squared copper electrodes in a potato load applying $1 \mathrm{kV} / \mathrm{cm}$. This test shows the proper operation of the developed versatile architecture and opens the door to new and innovative electroporation methods with improved performance. 


\section{Conclusions}

In this paper, a versatile power converter architecture has been presented oriented to generate high-voltage pulses required for irreversible electroporation. The proposed topology allows to generate configurable amplitude, polarity and length pulses and pulse trains with high rise times, enabling research on the influence of electrical impulses in IRE treatments.

The proposed topology has been designed and implemented leading to bipolar generator up to $4 \mathrm{kV}$ and $150 \mathrm{~A}$. Experimental results prove the feasibility of this proposal and opens new possibilities of research on cancer treatment using irreversible electroporation.

\section{ACKNOWLEDGEMENT}

This work was partly supported by the Spanish MINECO under Project TEC2013-42937R, Project CSD2009-00046, and Project RTC-2014-1847-6, by the DGA-FSE, and by the University of Zaragoza under Project JIUZ-2014-TEC-08.

\section{REFERENCES}

[1] F. Stephens and K. R. Aigner, Basics of Oncology: Springer-Verlag Berlin Heidelberg, 2009.

[2] D. Hanahan and R. A. Weinberg, "The Hallmarks of Cancer," Cell, vol. 100, pp. 57-70, $1 / 7 / 2000$.

[3] J. G. Kassakian and T. M. Jahns, "Evolving and Emerging Applications of Power Electronics in Systems," IEEE Journal of Emerging and Selected Topics in Power Electronics, vol. 1, pp. 47-58, 2013.

[4] T. Sai Chun, "A Low-Operating-Voltage Wireless Intermediate-Range Scheme for Energy and Signal Transmission by Magnetic Coupling for Implantable Devices," IEEE Journal of Emerging and Selected Topics in Power Electronics, vol. 3, pp. 242-251, 2015.

[5] J. Friedmann, F. Groedl, and R. Kennel, "A Novel Universal Control Scheme for Transcutaneous Energy Transfer (TET) Applications," IEEE Journal of Emerging and 
Selected Topics in Power Electronics, vol. 3, pp. 296-305, 2015.

[6] H. Akagi, "Classification, Terminology, and Application of the Modular Multilevel Cascade Converter (MMCC)," IEEE Transactions on Power Electronics, vol. 26, pp. 3119-3130, 2011.

[7] J. C. Weaver and Y. A. Chizmadzhev, "Theory of electroporation: A review," Bioelectrochemistry and Bioenergetics, vol. 41, pp. 135-160, 1996.

[8] T. Y. Tsong, "Electroporation of cell membranes," Biophysical Journal, vol. 60, pp. 297 $306,8 / / 1991$.

[9] W. J. Dower, J. F. Miller, and C. W. Ragsdale, "High efficiency transformation of E. coli by high voltage electroporation," Nucleic Acids Research, vol. 16, pp. 6127-6145, 1988.

[10]E. Neumann, M. Schaefer-Ridder, Y. Wang, and P. H. Hofschneider, "Gene transfer into mouse lyoma cells by electroporation in high electric fields," EMBO Journal, vol. 1, pp. 841-845, 1982.

[11]T. R. Gowrishankar, K. C. Smith, and J. C. Weaver, "Transport-Based Biophysical System Models of Cells for Quantitatively Describing Responses to Electric Fields," Proceedings of the IEEE, vol. 101, pp. 505-517, 2013.

[12]T. Kotnik, P. Kramar, G. Pucihar, D. Miklavcic, and M. Tarek, "Cell membrane electroporation- Part 1: The phenomenon," IEEE Electrical Insulation Magazine, vol. 28, pp. 14-23, 2012.

[13]S. Haberl, D. Miklavcic, G. Sersa, W. Frey, and B. Rubinsky, "Cell membrane electroporation-Part 2: the applications," IEEE Electrical Insulation Magazine, vol. 29, pp. 29-37, 2013.

[14]A. Golberg and M. L. Yarmush, "Nonthermal Irreversible Electroporation: Fundamentals, Applications, and Challenges," IEEE Transactions on biomedical Engineering, vol. 60, pp. 707-714, 2013.

[15]B. Rubinsky, G. Onik, and P. Mikus, "Irreversible electroporation: A new ablation modality - Clinical implications," Technology in Cancer Research and Treatment, vol. 6, pp. 37-48, 2007.

[16]R. V. Davalos, L. M. Mir, and B. Rubinsky, "Tissue ablation with irreversible electroporation," Annals of Biomedical Engineering, vol. 33, pp. 223-231, 2005. 
[17]A. Ivorra, "Tissue Electroporation as a Bioelectric Phenomenon: Basic Concepts," in Irreversible Electroporation, B. Rubinsky, Ed., ed: Springer Berlin Heidelberg, 2010, pp. 23-61.

[18]A. Ivorra and B. Rubinsky, "Historical Review of Irreversible Electroporation in Medicine," in Irreversible Electroporation, B. Rubinsky, Ed., ed: Springer Berlin Heidelberg, 2010, pp. 1-21.

[19]J. Chunlan, R. V. Davalos, and J. C. Bischof, "A Review of Basic to Clinical Studies of Irreversible Electroporation Therapy," IEEE Transactions on biomedical Engineering, vol. 62, pp. 4-20, 2015.

[20]R. E. Neal, P. A. Garcia, J. L. Robertson, and R. V. Davalos, "Experimental Characterization and Numerical Modeling of Tissue Electrical Conductivity during Pulsed Electric Fields for Irreversible Electroporation Treatment Planning," IEEE Transactions on biomedical Engineering, vol. 59, pp. 1076-1085, 2012.

[21]G. Pucihar, J. Krmelj, Rebers, x030C, M. ek, T. Napotnik, et al., "Equivalent Pulse Parameters for Electroporation," IEEE Transactions on biomedical Engineering, vol. 58, pp. 3279-3288, 2011.

[22]C. Bernal, O. Lucia, H. Sarnago, J. M. Burdío, A. Ivorra, and Q. Castellvi, "A Review of Pulse Generation Topologies for Clinical Electroporation," in IEEE Annual Conference of the Industrial Electronics Society, 2015, pp. 625-630.

[23]M. Rebersek, D. Miklavcic, C. Bertacchini, and M. Sack, "Cell membrane electroporation-Part 3: the equipment," IEEE Electrical Insulation Magazine, vol. 30, pp. 8-18, 2014.

[24]M. Sack and H. Bluhm, "New Measurement Methods for an Industrial-Scale Electroporation Facility for Sugar Beets," IEEE Transactions on Industry Applications, vol. 44, pp. 1074-1083, 2008.

[25]M. Sack, C. Schultheiss, and H. Bluhm, "Triggered Marx generators for the industrialscale electroporation of sugar beets," IEEE Transactions on Industry Applications, vol. 41, pp. 707-714, 2005.

[26] J. R. Grenier, S. H. Jayaram, M. Kazerani, W. Haifeng, and M. W. Griffiths, "MOSFETBased Pulse Power Supply for Bacterial Transformation," Industry Applications, IEEE Transactions on, vol. 44, pp. 25-31, 2008. 
[27]J. Clementson, K. Rahbarnia, O. Grulke, and T. Klinger, "Design of A, B, and C Pulse Forming Networks Using the VINPFN Application," Power Electronics, IEEE Transactions on, vol. 29, pp. 5673-5679, 2014.

[28]A. de Angelis, L. Zeni, and G. Leone, "Blumlein configuration for variable length highvoltage pulse generation by simultaneous switch control," Electronics Letters, vol. 42, pp. 205-207, 2006.

[29]M. Petkovsek, J. Nastran, D. Voncina, P. Zajec, D. Miklavcic, and G. Sersa, "High voltage pulse generation [electroporation]," Electronics Letters, vol. 38, pp. 680-682, 2002.

[30]O. Lucía, L. A. Barragán, J. M. Burdío, O. Jiménez, D. Navarro, and I. Urriza, "A versatile power electronics test-bench architecture applied to domestic induction heating," IEEE Transactions on Industrial Electronics, vol. 58, pp. 998-1007, March 2011. 